\title{
PILOT STUDY: EPIDEMIOLOGICALAND CLINICAL PROFILE OFPATIENTS WITH RHEUMATOID ARTHRITIS AT AN UNIVERSITY AMBULATORY CENTER IN THE CITY OF SÃO PAULO
}

Carolina Bassoli de Azevedo ${ }^{1, \star}$, Vitoria Morais Schimitberger ${ }^{1}$, Raynne Fantin Jozalaํ, Vitoria Gloria Felix de Campos ${ }^{1}$, Leonardo Mendes Bella'

1.Universidade Anhembi Morumbi, São Paulo (SP), Brazil.

*Corresponding author: carolbassoli@hotmail.com

\section{BACKGROUND}

To perform an analysis of the clinical-demographic characteristics of patients with rheumatoid arthritis (RA) being followed up in a service linked to a University in São Paulo.

\section{MATERIALS AND METHODS}

This is a retrospective epidemiological study of a group of patients with rheumatoid arthritis followed up at an integrated health center in the city of São Paulo. From 2016 to 2019, 179 medical records were evaluated at the rheumatology outpatient clinic. The data from the medical records were transcribed into a standardized table and validated by a rheumatologist.

\section{RESULTS}

Out of a total of 179 patients analyzed, about 18\% had systemic autoimmune diseases and about 11\% had rheumatoid arthritis. Of the total number of patients with rheumatoid arthritis, $90 \%$ were female, the mean age of the patients was 52.6 years. The disease activity was present in $65 \%$ of patients. The average illness time of 6.1 years. Only $29 \%$ of patients had comorbidities. The rheumatoid factor was positive in $50 \%$ of patients $(n=10)$. Regarding treatment, $50 \%$ of patients used immunobiologicals, $85 \%$ used methotrexate and $100 \%$ of patients used corticosteroids with adequate monitoring and weaning. The patients' disease activity was measured using the disease activity score (DAS28) and, as a result, $45 \%$ of the patients presented remission of the disease, $30 \%$ presented moderate disease activity and $25 \%$ presented high disease activity.

\section{CONCLUSION}

This study provided a partial view of the clinical-epidemiological profile of patients with RA followed by the university outpatient service in São Paulo (SP). There was a wide use of immunobiological drugs, which differs from the general epidemiological profile described in the scientific literature. In addition, the relatively high disease activity index in the group which use of immunobiologicals was $85 \%$ demonstrates that this group may not be benefiting from the use of medications. Therefore, in order to confirm the veracity of the presented data, it is necessary to follow the research. 